Vol. 2 No. 1, Juli 2021, hlm. 141 - 146

DOI: $\mathrm{xxxxxxxxxxxxxxxxxxxxxxxxxxx}$

Available online at http:// jurnal.stmikroyal.ac.id/index.php/j-com

\title{
PENERAPAN ARTIFICIAL INTELLIGENCE DALAM MENDIAGNOSA PENYAKIT AKIBAT PARASIT NYAMUK DENGAN METODE DEMPSTER SHAFER
}

\author{
Ragil Monicha Winahyu ${ }^{1}$, Iqbal Kamil Siregar ${ }^{2 *}$, Masitah Handayani ${ }^{3}$ \\ ${ }^{1}$ Mahasiswa Prodi Sistem Informasi, STMIK Royal \\ ${ }^{2}$ Prodi Sistem Komputer, STMIK Royal \\ ${ }^{3}$ Prodi Sistem Informasi, STMIK Royal \\ *email: iqbalkamilsiregar@royal.ac.id
}

\begin{abstract}
The climatic conditions in Indonesia are very vulnerable to the formation of breeding grounds for disease populations. There are many types of diseases that generally occur due to mosquito parasites including Dengue Hemorrhagic Fever (DHF), Typhoid Fever, Measles (Morbili), Malaria, and several other tropical diseases. Information from doctors is needed by all sick people, but is constrained by the problem of costs for such expensive treatment. That is the reason for making an expert system that can diagnose mosquito parasitic fever. This designed system uses the Dempster.- Shafer method. Dempster-shafers can be used to combine separate pieces of information to calculate one by one the probability of an event occurring. This application can diagnose diseases caused by mosquito parasites by entering the symptoms of the questions answered by the patient and getting maximum results. The system can run on web applications such as Google Chrome and Mozilla.The research was conducted at the Simpang Empat Health Center, Asahan Regency.
\end{abstract}

Keywords : Mosquito; Dempster Shafer; Health Center

\begin{abstract}
Abstrak : Kondisi iklim yang ada di Indonesia sangat rentan dengan pembentukan tempat berkembang biaknya populasi penyakit. Ada banyak jenis penyakit yang pada umumnya terjadi yaitu akibat parasit nyamuk diantaranya Demam Berdarah Dengue (DBD), Demam Tifoid, Campak (Morbili), Malaria, dan beberapa penyakit tropis lainnya. Informasi dari dokter dangat dibutuhkan oleh semua orang sakit, namun terkendala masalah biaya untuk perobatan yang begitu mahal. Itulah yang menjadi alasan untuk dibuatnya sebuah sistem pakar yang dapat mendiagnosa penyakit demam parasit nyamuk. Sistem yang dirancang ini menggunakan metode Dempster - Shafer. Dempster-shafer bisa digunakan untuk menggabungkan potonganpotongan informasi yang terpisah untuk menghitung satu persatu kemungkinan yang terjadi dari suatu peristiwa. Aplikasi ini bisa mendiagnosis penyakit akibat parasit nyamuk dengan memasukkan gejala pertanyaan yang dijawab oleh pasien dan mendapatkan hasil yang maksimal. Sistem dapat berjalan pada aplikasi web seperti google crhrome dan mozilla. Penelitian dilaksanakan di Puskesmas Simpang Empat Kabupaten Asahan.
\end{abstract}

Kata Kunci : Nyamuk; Dempster Shafer; Puskesmas 
Vol. 2 No. 1, Juli 2021, hlm. 141 - 146

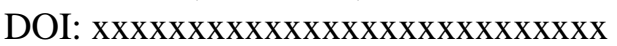

Available online at http:// jurnal.stmikroyal.ac.id/index.php/j-com

\section{PENDAHULUAN}

Salah satu negara yang mempunyai iklim tropis yaitu Indonesia, karena indonesia terletak tepat di garis khatulistiwa. Karena Indonesia Secara Geografis berada antara 6 LU - 11 LS dan 95 BT - 141 BT. Iklim tropis yang ada pada Indonesia menyebabkan berkembangnya beberapa penyakit yang umumnya terjadi di daerah tropis salah satunya di daerah Sumatera Utara tepatnya yaitu di Asahan. Iklim tropis sangat berkaitan dengan tempat berkembang biaknya agen penyakit. Beberapa penyakit pada umumnya terjadi akibat parasit nyamuk diantaranya: Demam Berdarah (DBD), Cikungunya, Penyakit Kuning, Kaki Gajah (Filariasis), Malaria, dan beberapa penyakit tropis lainnya.

Seiring dengan perkembangan teknologi ada yang mampu mengadopsi proses dan cara berpikir manusia yaitu teknologi Artificial Intelligence atau Kecerdasan Buatan [1]. Sistem pakar adalah salah satu bagian dari kecerdasan buatan (AI) yang mengandung pengetahuan tertentu sehingga setiap orang dapat menggunakannya untuk memecahkan berbagai masalah yang bersifat spesifik [2]. Dalam hal ini adalah permasalahan kesehatan seperti mendiagnosa penyakit demam parasit nyamuk. Ilmu artificial intellegence mempelajari tentang bagaimana cara agar mesin dapat bekerja dan memiliki kemampuan seperti manusia, mulai dari meniru cara otak manusia bekerja, meniru jaringan saraf [3].

Sangat dibutuhkannya informasi yang cepat dan akurat dari dokter oleh semua orang yang sakit, namun terkendala masalah biaya untuk perobatan yang begitu mahal. Hal inilah yang mendukung pembangunan sebuah sistem pakar untuk dapat mendiagnosa penyakit akibat parasit nyamuk. Diagnosa tersebut akan muncul dalam sistem, kemudian hasilnya akan disampaikan lagi ke pengguna. Diharapkan sistem ini mampu memberikan informasi yang optimal untuk memberikan solusi pada penanganan penyakit akibat parasit nyamuk pada puskemas Simpang Empat dengan tujuan untuk menghasilkan aplikasi sistem pakar yang mampu membantu mendiagnosa penyakit demam parasit nyamuk dan mengaplikasikan sistem pakar berbasis web untuk identifikasi penyakit demam parasit nyamuk. Menjadikan aplikasi konsultasi penyakit demam parasit nyamuk, sebagai sarana penyediaan informasi kepada seluruh masyarakat secara cuma-cuma disekitaran Puskesmas Simpang Empat.

\section{METODE}

Metode Dempster Shafer adalah teori matematika dimana tujuannya yaitu agar dapat menunjukkan bukti berdasarkan fungsi kepercayaan dan pemikiran yang masuk akal (belief function and plausible reasoning) [4]. Dimana dapat dipakai dalam menyatukan beberapa informasi yang sudah terpotong dan terpisah (bukti) dalam memastikan kemungkinan dari suatu kejadian. Untuk menggabungkan sebuah evidence dari sumber-sumber agar memberikan tingkat kepercayaan dari mengambil seluruh evidence yang tersedia juga merupakan cara yang diberikan oleh teori ini. Berikut Rumus Metode Dempster Shafer :

$$
M_{3}(Z)=\sum X \cap Z m 1(X) m 2(Y)
$$


Vol. 2 No. 1, Juli 2021, hlm. 141 - 146

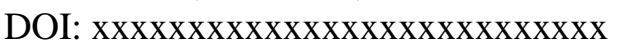

Available online at http:// jurnal.stmikroyal.ac.id/index.php/j-com

$$
\overline{\sum X \cap Y=0 m 1(X) m 2(Y)}
$$

\section{Dimana :}

$\mathrm{m} 1(\mathrm{X})$ adalah fungsi massa dari bukti $\mathrm{X}$ $\mathrm{m} 2$ (Y) adalah fungsi massa dari bukti Y m3(Z) adalah fungsi massa dari bukti Z $\kappa$ adalah jumlah bukti konflik [5].

Data yang digunakan dalam penelitian ini adalah data gejala yang terjadi pada penyakit akibat parasit nyamuk, terkumpulah data gejala-gejala dari demam akibat parasit nyamuk. Dimana data ini akan dijadikan variabel dengan angka untuk diproses oleh metode Dempster Shafer untuk menghasilkan sebuah diagnosa. Berikut adalah data gejala yang disusun untuk proses diagnosa yang akan diinputkan ke dalam sistem :

Tabel 1. Data Gejala

\begin{tabular}{|c|c|l|}
\hline No & Id Gejala & \multicolumn{1}{|c|}{ Gejala Penyakit } \\
\hline 1 & G001 & Rasa kedinginan disertai sakit kepala \\
\hline 2 & G002 & Menggigil kurang lebih lima belas menit sampai satu jam \\
\hline 3 & G003 & Kedingininan disertai panas tinggi \\
\hline 4 & G004 & Badan lemas dan mengigau \\
\hline 5 & G005 & Demam bisa terjadi sampai berhari-hari \\
\hline 6 & G006 & Beberapa bagian tubuh terasa sakit \\
\hline 7 & G007 & Kepala terasa sakit \\
\hline 8 & G008 & Tenggorokan juga terasa sakit \\
\hline 9 & G009 & Merasa sangat sakit dan Badan terasa lemah \\
\hline 10 & G010 & $\begin{array}{l}\text { Tangan serta kaki mengalami bintik merah setelah itu langsung } \\
\text { menyebar keseluruh badan. }\end{array}$ \\
\hline 11 & G011 & Demam sudah berlangsung dua sampai empat hari. \\
\hline 12 & G012 & $\begin{array}{l}\text { Linu pada persendian serta panas, kemudian nyeri pada tulang- } \\
\text { tulang, pegal dan ngilu. }\end{array}$ \\
\hline 13 & G013 & Tidak nafsu makan \\
\hline 14 & G014 & Mual diiringi muntah \\
\hline 15 & G015 & Panas tinggi kemudian melemahnya dneyut nadi \\
\hline 16 & G016 & Nyeri dada \\
\hline 17 & G017 & Muntah yang diikuti dengan pendarahan dari mulut, hidung, \\
\hline 18 & G018 & Nyeri mata \\
\hline 19 & G019 & Nyeri perut \\
\hline 20 & G020 & $\begin{array}{l}\text { Mengalami pembengkakan yang permanen di kaki,lengan serta } \\
\text { buah dada juga . }\end{array}$ \\
\hline
\end{tabular}

Berdasarkan pada data gejala pada point sebelumnya, maka untuk mencari rule dalam Dempster Shafer adalah sebagai berikut : (1) Rule 1 : If jenis gejala G008 AND 
Vol. 2 No. 1, Juli 2021, hlm. 141 - 146

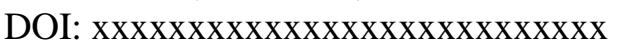

Available online at http:// jurnal.stmikroyal.ac.id/index.php/j-com

G009 AND G014 AND G015 Then Vektor Malaria., (2) Rule 2 : If Jenis gejala G001 AND G008 AND G010 AND G011 Then Demam Berdarah., (3) Rule 3 : If Jenis gangguan G005 AND G006 AND G009 AND G012 Then Demam Cikungunya.

Dari alur, rule dan tabel keputusan diatas, maka dapat dikonversikan menjadi aturan produksi. Aturan produksi dibentuk dari pengubahan tabel keputusan. Pembuatan suatu aturan dilakukan dengan beberapa tahapan. Berikut ini merupakan bentuk pengkonversian tabel keputusan menjadi aturan produksi : (1) IF ( Sakit Tenggorokan $A N D$ Merasa sangat sakit $A N D$ Mual dan muntah-muntah $A N D$ Demam tinggi dan denyut nadi lemah ) Then Vektor Malaria., (2) IF (Rasa kedinginan disertai sakit kepala $A N D$ Sakit tenggorokan Bintik Merah pada tangan dan kaki AND Demam sampai beberapa hari) Then Demam Berdarah., (3) IF ( Demam panas dingin AND Sakit dibeberapa bagian tubuh $A N D$ Badan terasa lemah $A N D$ Diikuti dengan linu dipersendian, timbulnya rasa pegal-pegal dan ngilu) Then Demam Cikungunya.

\section{HASIL DAN PEMBAHASAN}

Implementasi merupakan proses menjalankan hasil penelitian kedalam media nyata yang akan menghasilkan kesimpulan setelah dilakukan pengujian. Aplikasi yang telah selesai dirancang merupakan Implementasi dari sistem pakar Untuk Mendiagnosa Penyakit Akibat Parasit Nyamuk Dengan Metode Dempster Shafer. Konsep dasar dari aplikasi yang dirancang adalah melakukan pengumpulan dan penyusunan data gejala pada penyakit akibat parasit nyamuk, kemudian data yang dikumpulkan dikelola menggunakan metode Dempster Shafer untuk menghasilkan sebuah diagnosa. Untuk hasil tampilannya sebagai berikut:

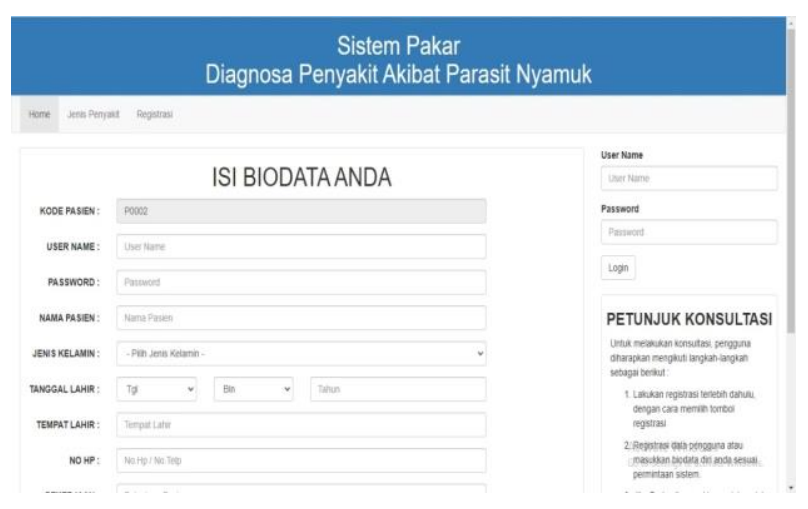

Gambar 1. Tampilan Registrasi

Tampilan ini menampilkan untuk pengisian data user yang belum ada datanya disimpan di dalam database sebelum melakukan login user untuk melakukan konsultasi penyakit akibat parasit nyamuk. 
Vol. 2 No. 1, Juli 2021, hlm. 141 - 146

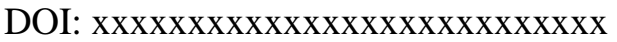

Available online at http:// jurnal.stmikroyal.ac.id/index.php/j-com

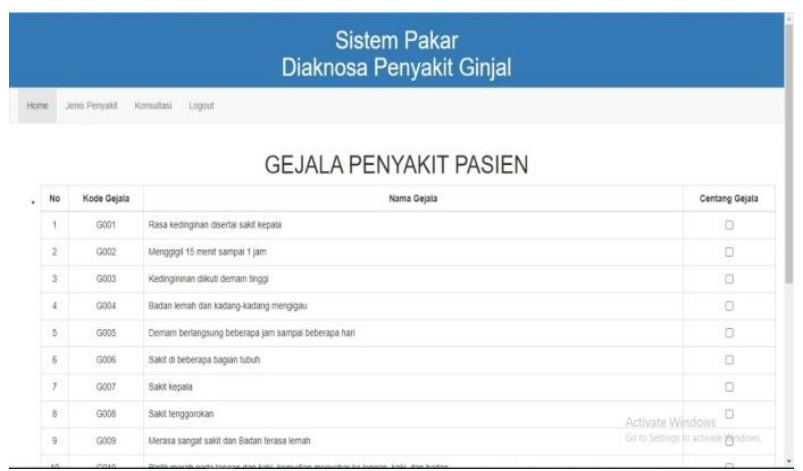

Gambar 2. Tampilan Konsultasi

Tampilan ini menampilkan gejala penyakit pasien akibat parasit nyamuk, agar user dapat mengetahui penyakit apa saja yang disebabkan akibat parasit nyamuk.

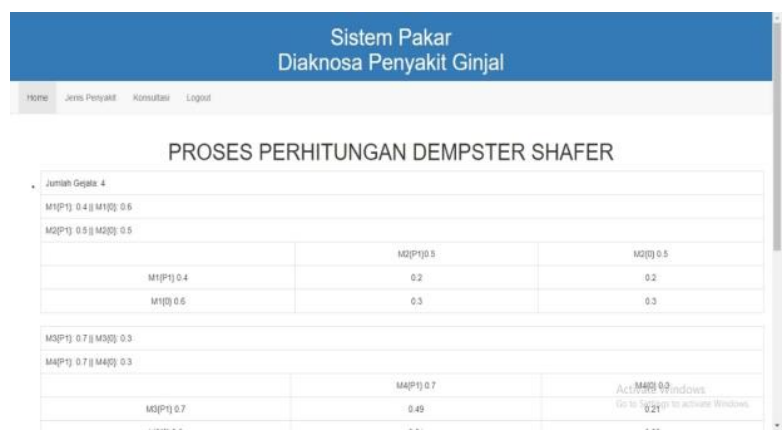

Gambar 3. Tampilan Proses Perhitungan

Tampilan ini merupakan cara menghitung yang dijalankan dengan memakai metode dempster shafer.

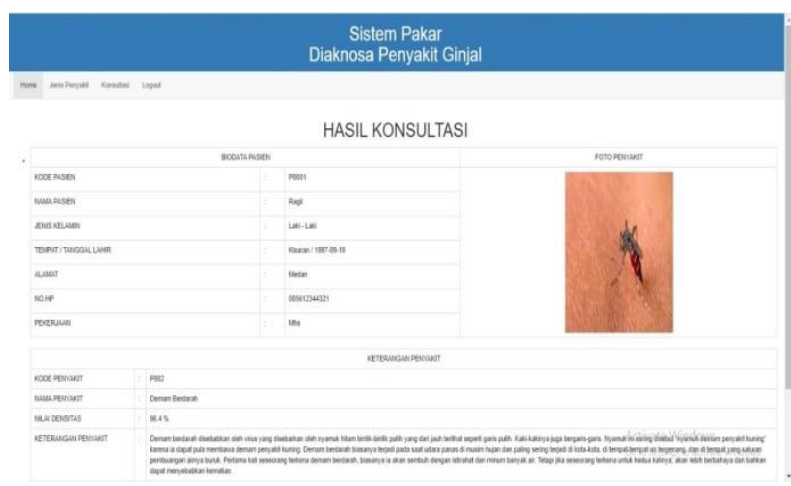

Gambar 4. Tampilan Hasil Diagnosa

Tampilan ini akan menampilkan hasil diagnosa pada hasil kosultasi user dengan sistem, sehingga user bisa mengetahui penyakit apa yang dialami oleh user tersebut dalam sistem penyakit akibat parasit nyamuk. 
Vol. 2 No. 1, Juli 2021, hlm. 141 - 146

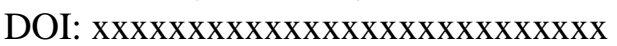

Available online at http:// jurnal.stmikroyal.ac.id/index.php/j-com

\section{SIMPULAN}

Dengan adanya sistem pakar diagnosis penyakit akibat parasit nyamuk dengan menggunakan metode dempster shafer maka dapat disimpulkan bahwa aplikasi ini bisa mendiagnosis penyakit akibat parasit nyamuk dengan memasukkan gejala pertanyaan yang dijawab oleh pasien dan mendapatkan hasil diagnosa. Aplikasi yang dirancang dengan menggunakan metode dempster shafer yang bisa mendiagnosis menurut gejala atau keluhan yang dirasakan dan sistem dapat berjalan pada aplikasi web seperti google chrome dan mozilla.

\section{DAFTAR PUSTAKA}

[1] H. Hamsinar, F. Musadat, and Rahayu, "Penerapan Metode Backward Chaining Pada Sistem Pakar Untuk Mendeteksi Penyakit Tanaman Jagung," J. Inform., vol. 8, no. 1, pp. 60-64, 2019.

[2] I. Mansyur and W. Kurniawan, "Sistem Pakar Mendiagnosa Penyakit Paru-Paru Pada Manusia Berbasis Web," Pros. Semin. Nas. Inov. Teknol., no. 2580-54950, pp. 28-38, 2017, [Online]. Available: waonek@ rocketmail.com.

[3] A. W. O. Gama, I. W. Sukadana, and G. H. Prathama, "Sistem Pakar Diagnosa Awal Penyakit Mata (Penelusuran Gejala Dengan Metode Backward Chaining)," J. Elektron. List. Telekomun. Komputer, Inform. Sist. Kontrol, vol. 1, no. 2, pp. 71-76, 2019, doi: 10.30649/j-eltrik.v1i2.34.

[4] M. Dahria, R. Silalahi, and M. Ramadhan, "Sistem Pakar Metode Damster Shafer untuk Menentukan Jenis Gangguan Perkembangan pada Anak," J. SAINTIKOM, vol. 12, no. 1, pp. 1-10, 2013.

[5] P. S. Hasibuan and M. I. Batubara, "Penerapan Metode Dempster Shafer Dalam Mendiagnosa Penyakit Faringitis," J. Media Inform. Budidarma, vol. 3, no. 1, p. 59, 2019, doi: 10.30865/mib.v3i1.1061. 